\title{
Association and interaction of PPAR-complex gene variants with latent traits of left ventricular diastolic function
}

\author{
Jyh-Ming Jimmy Juang 1,2,4, Lisa de las Fuentes ${ }^{\dagger 1}$, Alan D Waggoner1 ${ }^{1}$ C Charles Gu2,3 and Víctor G Dávila-Román*1
}

\begin{abstract}
Background: Abnormalities in myocardial metabolism and/or regulatory genes have been implicated in left ventricular systolic dysfunction. However, the extent to which these modulate left ventricular diastolic function (LVDF) is uncertain.

Methods: Independent component analysis was applied to extract latent LVDF traits from 14 measured echocardiography-derived endophenotypes of LVDF in 403 Caucasians. Genetic association was assessed between measured and latent LVDF traits and 64 single nucleotide polymorphisms (SNPs) in three peroxisome proliferatoractivated receptor (PPAR)-complex genes involved in the transcriptional regulation of fatty acid metabolism.

Results: By linear regression analysis, 7 SNPs (4 in PPARA, 2 in PPARGC1A, 1 in PPARG) were significantly associated with the latent LVDF trait, whereas a range of 0-4 SNPs were associated with each of the 14 measured echocardiographyderived endophenotypes. Frequency distribution of $P$ values showed a greater proportion of significant associations with the latent LVDF trait than for the measured endophenotypes, suggesting that analyses of the latent trait improved detection of the genetic underpinnings of LVDF. Ridge regression was applied to investigate within-gene and genegene interactions. In the within-gene analysis, there were five significant pair-wise interactions in PPARGC1A and none in PPARA or PPARG. In the gene-gene analysis, significant interactions were found between rs4253655 in PPARA and rs $1873532(p=0.02)$ and $r 57672915(p=0.02)$, both in PPARGC1A, and between rs1151996 in PPARG and rs4697046 in PPARGC1A $(p=0.01)$.
\end{abstract}

Conclusions: Myocardial metabolism PPAR-complex genes, including within and between genes interactions, may play an important role modulating left ventricular diastolic function.

\section{Background}

Both animal models of left ventricular (LV) pressureoverload and clinical studies in humans with hypertension implicate abnormal myocardial metabolism in the development of hypertensive heart disease (HHD) which is characterized by phenotypes such as LV hypertrophy $(\mathrm{LVH})$, left ventricular diastolic dysfunction (LVDD), left ventricular systolic dysfunction (LVSD), and/or the development of heart failure (HF). Myocardial fatty acid metabolism is a key modulator of HHD phenotypes and

* Correspondence: vdavila@wustl.edu

1 Cardiovascular Imaging and Clinical Research Core Laboratory, Cardiovascular Division, Department of Medicine, Washington University School of Medicine,

St. Louis, Missouri, USA

+ Contributed equally

Full list of author information is available at the end of the article peroxisome proliferator-activated receptor (PPAR)-complex genes play a critical role in regulating these metabolic processes [1-3].

The assessment of LV diastolic function (LVDF) by Doppler echocardiography is challenging due to the agedependency of measurements, the confounding effect of $\mathrm{LVH}$, and the non-linear distribution of many LVDF parameters such that no single measurement has emerged that defines LVDD [4-6]. As LVDD lies on a continuum between normal LVDF and diastolic heart failure (DHF), it represents a relevant clinical diagnosis for several reasons. LVDD, in the presence of normal LV systolic function, occurs in approximately $25 \%$ of adults 45 years of age or older and is a multivariate predictor of all-cause mortality after controlling for age, sex, and LVSD (haz- 
ards ratio $>8$ )[6]. The most severe form of LVDD, DHF, accounts for $40-50 \%$ of the approximately 5.7 million patients with HF in the US[7].

We have previously shown that independent component analysis (ICA)-derived latent traits of HHD can be used to enhance the detection of genetic association[8]. Herein we apply ICA to derive a single latent LVDF trait from multiple echocardiography-derived indices (or "endophenotypes") of LVDF. We tested the hypothesis that PPAR-complex gene variants modulate LVDF traits by examining individual SNP associations and withingene and gene-gene interaction effects.

\section{Methods}

\section{Study population}

Caucasian adults $(n=403)$ were analyzed from among a multi-racial cohort of consecutive subjects $(n=543)$ genotyped as part of a prospective genotype-phenotype association study of hypertensive heart disease at Washington University. Subjects exhibited a wide-range of cardiovascular and/or metabolic phenotypes, and also included healthy volunteers. Exclusion criteria included: 1) Hispanic ethnicity; 2) incomplete echocardiogram; 3) $\mathrm{LVH}$ due to conditions other than hypertension (i.e, hypertrophic cardiomyopathy); 4) significant valvular heart disease (regurgitation and/or stenosis > mild); or 5) significant systemic disease (i.e. malignancy, creatinine $\geq 0.22 \mathrm{mmol} / \mathrm{dL}[2.5 \mathrm{mg} / \mathrm{dL}])$.

Subject demographics were assessed by interview. Heart rate, blood pressure, and anthropomorphic measurements were obtained according to a standard protocol[9]. All subjects had blood drawn for fasting glucose, insulin, and lipids; DNA was extracted from peripheral blood leukocytes. The study was approved by the Human Research Protection Office at Washington University; all subjects provided written informed consent.

\section{Echocardiography}

The echocardiographic study was performed with an ultrasound system (Acuson-Siemens Sequoia, Mountain View, CA) using a 3.5-MHz array transducer. LV end-systolic and end-diastolic volumes were calculated according to the "method of discs" to derive LVEF (normal LV systolic function defined as LVEF $\geq 50 \%$ )[10]. LV mass was measured by the area-length method and indexed by height $^{2.7}\left(\mathrm{LVM} / \mathrm{Ht}^{2.7}\right)$ to adjust for body habitus[11]. LVH was defined as $\mathrm{LVM} / \mathrm{Ht}^{2.7}>51 \mathrm{~g} / \mathrm{m}^{2.7}$ for men and $>49.5 \mathrm{~g} /$ $\mathrm{m}^{2.7}$ for women[12]. Pulse-wave Doppler (PWD)-derived transmitral indices were recorded from the four-chamber view at the mitral valve leaflet tips to determine the early diastolic transmitral (E-wave) and atrial (A-wave) velocities $(\mathrm{m} / \mathrm{s})$, the E/A wave velocity ratio, E-wave deceleration time (DT, in $\mathrm{ms}$ ); the isovolumic relaxation time (IVRT, in ms) was measured by continuous-wave Doppler from the apical 5-chamber view[13]. Tissue Doppler Imaging (TDI)-derived early diastolic myocardial velocity was obtained from a $2.5 \mathrm{~mm}$ sample at the septal and lateral mitral annulus in the apical four-chamber view ( $E_{\text {sep }}^{\prime}$ and $\mathrm{E}_{\text {lat }}^{\prime}, \mathrm{A}_{\text {sep }}^{\prime}$ and $\mathrm{A}_{\text {lat }}^{\prime}$, respectively, in $\mathrm{cm} / \mathrm{s}$ ) with the average value represented as a "global" value $\left(\mathrm{E}_{\mathrm{gl}}^{\prime}\right.$ and $\mathrm{A}_{\mathrm{gl}}^{\prime}$, in $\mathrm{cm} / \mathrm{s}$ ) [13-15]. The mitral E-wave/E' ratio was calculated to estimate the $L V$ filling pressure $\left(E / E_{\text {sep }}^{\prime}, E / E_{\text {lat }}^{\prime}\right.$, and $\left.E / E_{g l}^{\prime}\right)[16,17]$. All reported measurements represent the average of three consecutive cardiac cycles obtained by a single observer blinded to clinical status. The intraclass correlation coefficients for echocardiographic indices measured in our lab are: $0.75-0.88$ for LV structure (i.e., LV mass/volumes) and 0.82-0.97 for PWD- and TDIderived indices of LV diastolic function (i.e., E-, A-waves, DT, IVRT, and E').

\section{PPAR-complex genes genotyping and quality control}

SNPs in three PPAR-complex genes (i.e., PPARA, PPARG, and $P P A R G C 1 A$ ) were genotyped using Illumina BeadArray technology; 22 PPARA, 17 PPARG, and 39 $P P A R G C 1 A$ were selected to provide dense coverage and for compatibility in the multiplex reactions. Excluded from analysis were SNPs a) that deviated from HardyWeinberg equilibrium (HWE, $\mathrm{p}<0.01$ ), b) with minor allele frequency $\leq 5 \%$, and/or c) with genotype call rates $\leq 90 \%$. Maximal tolerated individual missing rate was $50 \%$.

\section{Statistical analysis}

\section{A. Extract latent LVDF trait by ICA}

Initial quality control was performed on each of the echocardiography-derived endophenotypes by univariate analysis; those with an absolute skewness $>1.5$ or absolute kurtosis $>2.0$ were log-transformed for the factor analysis. Potential confounding effects were adjusted by regression of the values over a cubic age polynomial within sex group; residuals from the regression were used for ICA and further analyses.

We used a freely available implementation called FastICA (version 1.9) available in $R$ (v. 2.7.0) to analyze the residuals of a matrix of the echocardiography-derived endophenotypes by pre-specified numbers of latent components $[8,18,19]$. For each component, the output from ICA consists of the extracted independent component (IC) represented by column vectors of the matrix of loadings on the echocardiography-derived endophenotypes and the coefficients of the extracted IC for each subject. The coefficients were then used to represent the individual latent LVDF trait values in subsequent analyses. Spearman's correlation between several traditional risk factors (systolic and diastolic blood pressure, body mass index, insulin, total cholesterol, triglycerides, LDL-C, HDL-C) and the latent LVDF trait were performed. 


\section{B. Select latent LVDF trait from extracted ICs}

Loadings of each IC were examined for overrepresentation of the echocardiography-derived endophenotypes, which may reflect the importance of a particular IC. Individual IC's were treated as a potential latent LVDF trait and its clinical characteristics were characterized by examining risks of LVDF in cohorts defined by the median of corresponding IC coefficients (groups assigned as "High-Risk" and "Low-Risk"). The means of each of the 14 echocardiography-derived phenotypes were compared to gauge the IC's capability of separating risks. Three expert echocardiographers (JMJ, LdlF, VGD$\mathrm{R}$ ) independently assessed the distributional characteristics of these measures and selected the IC that yielded the most clinically relevant separation between groups; by consensus the IC was selected to represent the latent LVDF trait for subsequent analysis.

\section{Genetic association analysis of the selected latent LVDF} trait

HWE was tested by $x^{2}$ test with 1 degree of freedom to identify SNPs with potential systematic bias resulting from genotyping errors. Linear regression analysis was performed to test for associations between the selected latent LVDF trait (represented by the IC coefficient) and the PPAR-complex candidate SNPs. In each regression model, covariates for age, sex, hypertension status, and $\mathrm{LVM} / \mathrm{Ht}^{2.7}$ were included. All regression analyses of genetic association were performed by SAS (v. 9.1.3, SAS Institute Inc., Cary, NC).

\section{Explore potential SNP-SNP (within-gene and gene-gene) interactions}

For identification of SNP-SNP interactions of potential importance to LVDD, a two-step procedure was applied: Step 1) detection of interactions within individual candidate genes (within-gene), and Step 2) identification of between-gene interactions (gene-gene). To deal with the large number of variables representing individual SNPs, their interactions, and their potential for collinearity, ridge regression analysis was performed ( $R$ package "penalized" version 0.9); ridge regression effectively eliminates many variables that are irrelevant to the trait of interest and effectively eliminates the collinearity problem[20,21]. In Step 1, for each candidate gene, ridge regression was applied to a model including all SNPs within that gene and their pair-wise interactions. SNPs that had main and/or interaction effects selected by the ridge regression were retained. In Step 2, all retained SNPs and their pairwise interactions (including those between genes) were entered into a general model. Ridge regression was again applied to the general model to identify a final set of important SNPs and interactions that together is significantly associated with the LVDD trait. Finally, conventional linear regression was applied to the selected SNPs and interactions to derive the significance levels of the associations.

\section{E. Statistical power and adjustment for multiple testing}

Quanto (v.1.2, http://hydra.usc.edu/gxe) was used to estimate statistical power (set at $80 \%$ at a significance level of 0.05 with a 2-sided alternate hypothesis)[22]. The power calculation assumed that an associated SNP has minor allele frequency of 0.2 and a locus-specific heritability of at least $2 \%$. To adjust for multiple testing, the method of false discovery rate was applied in SAS.

\section{Results}

\section{Clinical and echocardiographic characteristics}

The clinical and echocardiographic characteristics are shown in Tables 1 and 2, respectively. The majority of subjects had normal LV systolic function; mild LV systolic dysfunction (LVEF 40-49\%) was present in only $1.9 \%$ of the population; $17 \%$ of subjects had LVH. Distributional characteristics of the variables are shown in Additional File 1, Table S1.

\section{Extraction and identification of latent LVDF components} ICA analyses were performed by extracting 2, 3, and 6 components. Each extracted latent LVDF component was denoted by a letter "E", followed by a first digit which denoted the predefined number of components, and a secondary digit which denoted the individual component. For example, E21 refers to the first extracted component of a total of 2 latent components (Figure 1; figures for all extracted components in Additional File 1, Figures S1-S3). The collective loading pattern across the echocardiography-derived endophenotypes reflects the capability

\section{Table 1: Clinical characteristics of study subjects $(n=403)$.}

\begin{tabular}{lc}
\hline Age $(\mathrm{yrs})$ & $50 \pm 13$ \\
$\mathrm{BMI}\left(\mathrm{kg} / \mathrm{m}^{2}\right)$ & $30 \pm 6$ \\
Male, $\mathrm{n}(\%)$ & $187(46)$ \\
$\mathrm{SBP}(\mathrm{mmHg})$ & $123 \pm 16$ \\
DBP $(\mathrm{mmHg})$ & $79 \pm 9$ \\
Heart rate (beats per min) & $66 \pm 11$ \\
Diabetes mellitus, $\mathrm{n}(\%)$ & $57(14)$ \\
Hypertension, $\mathrm{n}(\%)$ & $147(37)$ \\
Creatinine (mg/dL) & $0.9 \pm 0.2$ \\
Glucose (mg/dL) & $95 \pm 27$ \\
Total Cholesterol (mg/dL) & $195 \pm 36$ \\
Triglycerides (mg/dL) & $140 \pm 93$ \\
LDL-C (mg/dL) & $115 \pm 31$ \\
HDL-C (mg/dL) & $53 \pm 15$ \\
\hline
\end{tabular}

Values represent the means \pm 1 standard deviation or the number (\%). BMI, body mass index; DBP, diastolic blood pressure; HDL-C, high density lipoprotein cholesterol; LDL-C, low density lipoprotein cholesterol; SBP, systolic blood pressure. 


\section{Table 2: Echocardiographic measurements of study population $(n=403)$.}

\begin{tabular}{|c|c|}
\hline LVEF (\%) & $64 \pm 6$ \\
\hline $\operatorname{LVM} / \mathrm{Ht}^{2.7}\left(\mathrm{~g} / \mathrm{m}^{2.7}\right)$ & $41.5 \pm 10.1$ \\
\hline E-wave (m/s) & $0.72 \pm 0.16$ \\
\hline A-wave $(\mathrm{m} / \mathrm{s})$ & $0.57 \pm 0.17$ \\
\hline E/A ratio & $1.35 \pm 0.48$ \\
\hline DT (ms) & $207 \pm 38$ \\
\hline IVRT (ms) & $94 \pm 18$ \\
\hline LA diameter $(\mathrm{cm})$ & $3.9 \pm 0.5$ \\
\hline $\mathrm{E}_{\mathrm{sep}}^{\prime}(\mathrm{cm} / \mathrm{s})$ & $10.1 \pm 2.7$ \\
\hline $\mathrm{E}_{\text {lat }}^{\prime}(\mathrm{cm} / \mathrm{s})$ & $13.2 \pm 3.5$ \\
\hline $\mathrm{E}_{\mathrm{gl}}^{\prime}(\mathrm{cm} / \mathrm{s})$ & $11.7 \pm 2.9$ \\
\hline$A_{\text {sep }}^{\prime}(\mathrm{cm} / \mathrm{s})$ & $10.8 \pm 1.7$ \\
\hline$A_{\text {lat }}^{\prime}(\mathrm{cm} / \mathrm{s})$ & $10.8 \pm 2.2$ \\
\hline$A_{g l}^{\prime}(\mathrm{cm} / \mathrm{s})$ & $10.8 \pm 1.7$ \\
\hline$E / E_{\text {sep }}^{\prime}$ & $7.5 \pm 2.4$ \\
\hline$E / E_{\text {lat }}^{\prime}$ & $5.8 \pm 2.0$ \\
\hline $\mathrm{E} / \mathrm{E}_{\mathrm{gl}}^{\prime}$ & $6.5 \pm 2.1$ \\
\hline LV diastolic septal wall (cm) & $1.0 \pm 0.2$ \\
\hline $\begin{array}{l}\text { LV diastolic posterior wall } \\
(\mathrm{cm})\end{array}$ & $1.0 \pm 0.1$ \\
\hline LV systolic diameter (cm) & $3.2 \pm 0.5$ \\
\hline LV diastolic diameter (cm) & $5.0 \pm 0.5$ \\
\hline$\%$ of subjects with LVH & $17.4 \% *$ \\
\hline
\end{tabular}

$A$, late diastolic mitral flow velocity; $\mathrm{DT}$, deceleration time; $\mathrm{E}$, early diastolic mitral flow velocity; $\mathrm{EF}$, ejection fraction; $\mathrm{E}_{\mathrm{gl}}^{\prime}, \mathrm{E}_{\text {lat' }}^{\prime} \mathrm{E}_{\text {sep }}{ }^{\prime}$ early diastolic mitral annular velocity (global, lateral, and septal, respectively); $E / E_{g^{\prime}}^{\prime}, E / E^{\prime a t}{ }^{\prime}, E / E_{\text {sep, }}^{\prime}$, ratio of early mitral flow to the early mitral annular velocity (global, lateral, and septal, respectively); IVRT, isovolumic relaxation time; LA, left atrial; LV, left ventricular.

${ }^{*}$ male $18.1 \%$, female $16.6 \%$

of a component to summarize a common source of regulation or an underlying interaction observed among genes. The component E61 had the highest loadings on $E_{\text {sep }}^{\prime}, E_{\text {lat, }}^{\prime} E_{\text {gl }}^{\prime}, E / E_{\text {sep }}^{\prime}, E / E_{\text {lat, }}^{\prime}$ and $E / E_{\text {gl }}^{\prime}$ compared to all other components in the loading of plots (Figure 1) and was thus selected as the latent LVDF endophenotype (Additional File 1, Table S2). The Spearman's correlation coefficients between several traditional risk factors (systolic and diastolic blood pressure, body mass index, insulin, total cholesterol, triglycerides, LDL-C, HDL-C) and the latent LVDF trait were determined (Additional File 1, Table S3). With the exception of LDL-C and total cholesterol, the remaining risk factors were significantly correlated with the latent LVDF trait.

\section{Ascertainment of quality of selected latent LVDF trait} The entire cohort was grouped as "High Risk" or "Low Risk" based on the medians of the individual latent LVDF trait values (i.e. individual ICs corresponding to each extracted component). Clinical characteristics and echocardiographic measurements in the "High-risk" and "Low-risk" groups are shown in Table 3 and Table 4, respectively. E61 resulted in the highest loadings on the TDI-derived echocardiographic variables, and thus, resulted in the most distinct separation of these LVDF echocardiography-derived measures (Additional File 1, Tables S4-6).

\section{Genetic association analysis of the latent LVDF trait}

After applying exclusion criteria, the resultant dataset consisted of 64 SNPs (15 PPARA, 14 PPARG, and 34 PPARGC1A). Individual locus information including allele frequencies and HWE p-values for all 78 SNPs (Additional File 1, Tables S6A-C) and the Haploview linkage disequilibrium displays for each gene (Additional File 1, Figures S4-6) are shown in the supplement. By linear regression analysis of single SNPs (after adjustment for covariates), 7 SNPs (4 in PPARA, 2 in PPARGC1A, 1 in $P P A R G)$ were significantly associated with the latent LVDF trait (E61), whereas a range of 0 to 4 SNPs were associated with each of the 14 echocardiography-derived endophenotypes (Table 5). The frequency distribution of the $\mathrm{P}$ values derived from the latent LVDF trait exhibited a higher degree of statistical significance than those derived from the echocardiography-derived endophenotypes (Additional File 1, Figure S7).

\section{Within-gene and gene-gene interactions}

In the within-gene analysis, significant SNPs (8 in PPARA, 12 in PPARGC1A, and 4 in PPARG) for each of the three genes were retained for the final best-fit model (log likelihood: -276.1, -281.2 and -281.6, respectively; Table 6 and Figure 2). PPARGC1A SNPs rs12500214 significantly interacted with both rs 2970847 and rs7672915 $(\mathrm{p}=0.02$ and 0.009 , respectively); rs768695 significantly interacted with both rs2970847 and rs2970853 (both $\mathrm{p}=$ $0.03)$; and rs4235308 significantly interacted with rs7672915 $(\mathrm{p}=0.007)$. No significant within-gene interactions were found among PPARA and PPARG SNPs.

In the gene-gene analysis, rs4253655 in PPARA significantly interacted with $\operatorname{rs} 1873532(\mathrm{p}=0.02)$ and rs7672915 $(\mathrm{p}=0.02)$, both in PPARGC1A. Significant interactions were also found between rs1151996 in PPARG and rs4697046 in PPARGC1A ( $\mathrm{p}=0.01)$. No gene-gene interactions were found between PPARA and PPARG genes.

\section{Power calculation and false discovery rate}

The study sample of 403 subjects provided adequate power to detect association of any SNP with a heritability $\geq 0.02$ and an allele frequency $\geq 0.2$ (power $\geq 81 \%$, significance level $\alpha=0.05$ ). Although there was a significant association for several individual SNPs in single SNP 


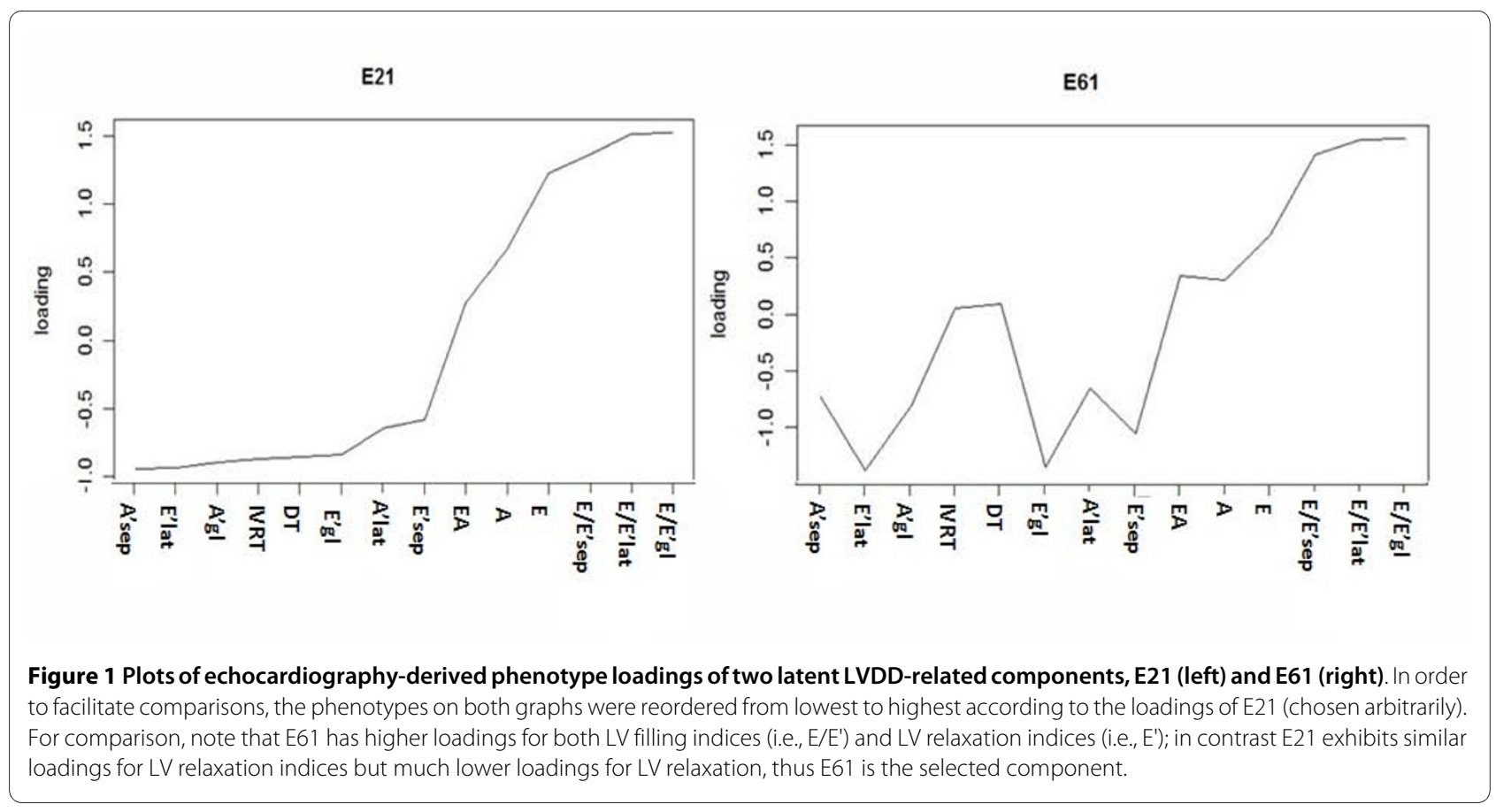

analysis, none remained significant after adjustment for multiple testing by the False Discovery Rate.

\section{Discussion}

In this study, we show genetic association between echocardiography-derived endophenotypes of LVDF and SNPs in three PPAR-complex genes involved in the transcriptional regulation of fatty acid metabolism. ICA was used to extract latent LVDF traits from 14 echocardiogra- phy-derived endophenotypes used clinically to evaluate diastolic function. We found that the latent LVDF trait identified relevant profiles of echocardiography-derived endophenotypes that could be clinically recognized as representing individuals of either High- or Low-Risk of LVDD. By use of linear regression analysis, 7 SNPs (4 in PPARA, 2 in PPARGC1A, 1 in PPARG) were significantly associated with the latent LVDF trait. In PPARA, 2 SNPs were clustered around intron 6 and two were in introns

Table 3: Clinical characteristics of the high-risk $(n=201)$ and low-risk groups $(n=202)$ using E61.

\begin{tabular}{|c|c|c|}
\hline & Low-Risk Group & High-Risk Group \\
\hline Age (yrs) & $49.4 \pm 13.0$ & $50.6 \pm 12.0$ \\
\hline $\mathrm{BMI}\left(\mathrm{kg} / \mathrm{m}^{2}\right)$ & $31.5 \pm 5.5$ & $28.2 \pm 6.4$ \\
\hline Male, n (\%) & $88(44)$ & 99 (49) \\
\hline $\mathrm{SBP}(\mathrm{mmHg})$ & $125 \pm 17$ & $121 \pm 16$ \\
\hline $\mathrm{DBP}(\mathrm{mmHg})$ & $81 \pm 9$ & $77 \pm 8$ \\
\hline Heart rate (beats per min) & $67 \pm 11$ & $65 \pm 11$ \\
\hline Diabetes mellitus, n (\%) & $39(19)$ & $18(9)$ \\
\hline Hypertension, n (\%) & $81(40)$ & $66(33)$ \\
\hline Creatinine (mg/dL) & $0.8 \pm 0.2$ & $0.9 \pm 0.2$ \\
\hline Glucose (mg/dL) & $98 \pm 31$ & $92 \pm 23$ \\
\hline Total Cholesterol (mg/dL) & $197 \pm 35$ & $193 \pm 36$ \\
\hline Triglycerides (mg/dL) & $150 \pm 85$ & $129 \pm 99$ \\
\hline $\mathrm{LDL}-\mathrm{C}(\mathrm{mg} / \mathrm{dL})$ & $116 \pm 31$ & $112 \pm 31$ \\
\hline $\mathrm{HDL}-\mathrm{C}(\mathrm{mg} / \mathrm{dL})$ & $51 \pm 14$ & $56 \pm 15$ \\
\hline
\end{tabular}

Values represent the means \pm 1 standard deviation or the number (\%). BMI, body mass index; DBP, diastolic blood pressure; HDL-C, high density lipoprotein cholesterol; LDL-C, low density lipoprotein cholesterol; SBP, systolic blood pressure. 
Table 4: Descriptive statistics for primary echocardiographic endophenotypes in E61.

\begin{tabular}{|c|c|c|}
\hline & Low-Risk Group & High-Risk Group \\
\hline$E(m / s)$ & $0.67 \pm 0.14$ & $0.76 \pm 0.16$ \\
\hline$A(m / s)$ & $0.52 \pm 0.15$ & $0.63 \pm 0.18$ \\
\hline$E / A$ & $1.41 \pm 0.52$ & $1.30 \pm 0.42$ \\
\hline $\mathrm{DT}(\mathrm{ms})$ & $210 \pm 39$ & $204 \pm 37$ \\
\hline IVRT (ms) & $95 \pm 19$ & $92 \pm 18$ \\
\hline $\mathrm{E}_{\mathrm{lat}}^{\prime}(\mathrm{cm} / \mathrm{s})$ & $14.7 \pm 3.3$ & $11.8 \pm 3.1$ \\
\hline $\mathrm{E}_{\mathrm{sep}}^{\prime}(\mathrm{cm} / \mathrm{s})$ & $11.1 \pm 2.8$ & $9.1 \pm 2.1$ \\
\hline $\mathrm{E}_{\mathrm{gl}^{\prime}}(\mathrm{cm} / \mathrm{s})$ & $12.9 \pm 2.9$ & $10.4 \pm 2.4$ \\
\hline $\mathrm{A}_{\mathrm{lat}}^{\prime}(\mathrm{cm} / \mathrm{s})$ & $10.6 \pm 2.3$ & $11.0 \pm 2.0$ \\
\hline$A_{\text {sep }}^{\prime}(\mathrm{cm} / \mathrm{s})$ & $10.8 \pm 1.8$ & $10.7 \pm 1.6$ \\
\hline$A_{g \mid}^{\prime}(\mathrm{cm} / \mathrm{s})$ & $10.7 \pm 1.8$ & $10.9 \pm 1.5$ \\
\hline$E / E_{\text {lat }}^{\prime}$ & $4.7 \pm 1.0$ & $6.9 \pm 2.2$ \\
\hline $\mathrm{E} / \mathrm{E}_{\mathrm{sep}}^{\prime}$ & $6.3 \pm 1.3$ & $8.7 \pm 2.5$ \\
\hline$E / E_{g l}^{\prime}$ & $5.3 \pm 1.1$ & $7.6 \pm 2.2$ \\
\hline
\end{tabular}

Values represent the means \pm 1 standard deviation. $A$, late diastolic transmitral inflow velocity; $\mathrm{A}_{\mathrm{gl}}^{\prime} \mathrm{A}_{\text {lat }}^{\prime} \mathrm{A}_{\mathrm{sep}}^{\prime}$, late diastolic mitral annular

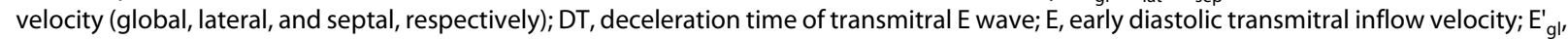
$\mathrm{E}_{\text {lat, }}^{\prime} \mathrm{E}_{\text {sep, }}$, early diastolic mitral annular velocity (global, lateral, and septal, respectively); $\mathrm{E} / \mathrm{E}_{\mathrm{gl}}^{\prime}, \mathrm{E} / \mathrm{E}_{\text {lat, }}^{\prime} \mathrm{E} / \mathrm{E}_{\text {sep, }}^{\prime}$, ratio of early transmitral flow to the early mitral annular velocity (global, lateral, and septal, respectively); IVRT, isovolumic relaxation time.

$1 \mathrm{~A}$ and $2 \mathrm{~A}$, adjacent to alternate promoters. The significant PPARGC1A SNPs were located in introns 1 and 7. The single significant PPARG SNP (rs3856806) is a synonymous coding SNP in Exon 7 (H447H).

Complex phenotypes such as LVDF arise from multiple gene-gene and gene-environment interactions, each contributing a small effect to the overall expression of the trait. A consideration of epistasis, or gene-gene interactions, may identify a portion of the unexplained risk (i.e., "missing heritability" [23]) noted in the overwhelming majority of genetic studies of complex diseases. It is therefore of particular importance to investigate potential gene-gene interactions in the complex mechanisms responsible for LVDF. In the present study, an exploratory analysis of SNP-SNP interactions by ridge regression yielded potentially important findings. First, significant associations detected by modeling both main effects and interactions were largely different from those by main effects alone; with the only exception of rs3856806, which had a relatively strong marginal effect, suggesting that the single-SNP scan approach may only be appropriate for variants with strong signals. Second, all gene-gene interactions involved PPARGC1A, probably reflecting the important regulatory role of this gene. Thus, metabolic modulation of left ventricular diastolic function by PPAR-complex genes may be an important mechanism in the development of LVDD and may contribute to the pathogenesis of DHF. This is the first study to show a genetic association between LVDF and PPAR-complex genes in humans.

\section{Regulation of myocardial metabolism and cardiac structure/function by PPAR-complex}

Alterations in myocardial fatty acid metabolism have been shown in both animal models and in humans to be an important determinant of the presence and development of hypertensive heart disease-related traits including hypertension, LVH, LVSD, and LVDD[3,24]. The normal fasting adult mammalian heart derives approximately two-thirds of ATP from the oxidation of fatty acids [25]. Under normal physiologic conditions, the heart is able to switch the energy substrate utilization from fatty acid to carbohydrates during the fed state, however under pathologic conditions the heart loses this metabolic plasticity[26]. For example, our group has previously shown that fatty acid metabolism is decreased in patients with heart failure and is a strong predictor of LV mass in patients with hypertension and in normotensive controls[27]. Metabolic modulation of the heart occurs primarily at the transcriptional level through the coordinated regulation of enzymes and proteins in specific metabolic pathways. PPAR-complex genes, transcription factors and coactivators known to regulate the expression of fatty acid transport and oxidation genes, have been shown in elegant transgenic models to modulate the pathophysiology of LV systolic and diastolic dysfunction[3,28-36]. The PPARA gene has been identified as a 
Table 5: P-values of genetic association study for candidate SNPs with lent LVDD trait: ICA and 14 echocardiography-derived endophenotypes.

\begin{tabular}{|c|c|c|c|c|c|c|c|c|c|c|c|c|c|c|c|c|c|}
\hline \multirow[t]{2}{*}{ Locus } & \multirow{2}{*}{$\begin{array}{c}\text { Gene } \\
\text { context }\end{array}$} & \multirow{2}{*}{$\begin{array}{l}\text { ICA } \\
\text { E61 }\end{array}$} & \multirow[t]{2}{*}{ Risk allele } & \multicolumn{14}{|c|}{ Echocardiography-derived LVDF endophenotypes } \\
\hline & & & & E & A & $E / A$ & DT & IVRT & E'sep & E'lat & E'gl & E/E'sep & E/E'lat & E/E'gl & A'sep & A'lat & A'gl \\
\hline \multicolumn{18}{|l|}{ PPARGC1A } \\
\hline rs12500214 & $1-2$ & & & & 0.01 & & & & & 0.02 & 0.04 & & & & 0.026 & 0.028 & 0.009 \\
\hline rs3736265 & $E-9$ & & & & & & 0.03 & & & & & & & & & & \\
\hline rs3755862 & $1-7$ & 0.038 & A & & & & 0.03 & & & & & & & & & & \\
\hline rs3774902 & $\mathrm{I}-1$ & 0.034 & $\mathrm{~T}$ & & & & & & & & & & & & & & \\
\hline rs3774921 & $\mathrm{I}-10$ & & & 0.021 & & & & & & & & & & & & & \\
\hline rs768695 & $\mathrm{I}-12$ & & & & & & & & & & & & & & & 0.011 & 0.018 \\
\hline rs7672915 & $1-2$ & & & & & & & & & & & 0.049 & & & & & \\
\hline rs7677000 & $1-2$ & & & & & & & & & 0.04 & & & & & & & \\
\hline \multicolumn{18}{|l|}{ PPARA } \\
\hline rs4253623 & $\mathrm{I}-1 \mathrm{~A}$ & 0.045 & G & & & & 0.04 & & & & & & & & & & \\
\hline rs4253655 & I-B & & & & & & & & & & & & & & & 0.028 & 0.043 \\
\hline rs4253681 & $\mathrm{I}-2 \mathrm{~A}$ & 0.039 & c & & & & & & & & & & & & 0.005 & & 0.009 \\
\hline rs4253725 & $1-3$ & & & 0.042 & & & & & & & & & & & & 0.044 & \\
\hline rs4253760 & $1-6$ & 0.021 & G & & & & 0.04 & & & & & & 0.02 & & & & \\
\hline rs4253765 & $I-6$ & 0.02 & C & & & & & & & & & & 0.02 & & & & \\
\hline \multicolumn{18}{|l|}{ PPARG } \\
\hline rs1797912 & $\mathrm{I}-1$ & & & & & & & & & & & 0.026 & & & & & \\
\hline rs2972162 & $1-4$ & & & & 0.04 & & & & & & & & 0.02 & 0.029 & & & \\
\hline rs3856806 & $E-7$ & 0.006 & $\mathrm{~T}$ & & & & & & & & & & & & & & \\
\hline
\end{tabular}

$\mathrm{E}-$, exon; $\mathrm{I}$-, intron. Only $\mathrm{p}$ values $<0.05$ are shown. 
Table 6: Significant Gene-Gene interactions in three PPAR-complex genes with latent LVDD endophenotype (E61).

\begin{tabular}{|c|c|c|c|c|c|c|c|c|}
\hline Gene & Locus & $\begin{array}{c}\text { Gene } \\
\text { Context }\end{array}$ & $\begin{array}{c}\text { Main } \\
\text { Effect }\end{array}$ & $\begin{array}{c}\mathbf{P} \\
\text { Value }\end{array}$ & $\begin{array}{l}\text { Within-Gene } \\
\text { Interaction }\end{array}$ & $\begin{array}{c}P \\
\text { value }\end{array}$ & $\begin{array}{l}\text { Gene-Gene } \\
\text { Interaction }\end{array}$ & $\begin{array}{c}P \\
\text { Value }\end{array}$ \\
\hline PPARGC1A & rs12500214 & Intron 2 & $Y$ & 0.047 & $\begin{array}{c}\mathrm{Y} \\
(\mathrm{rs} 2970847)\end{array}$ & 0.0278 & $\mathrm{~N}$ & 0.0094 \\
\hline PPARGC1A & rs7672915 & Intron 2 & $\mathrm{~N}$ & & $\begin{array}{c}Y \\
\text { (rs12500214) }\end{array}$ & 0.0092 & $\mathrm{~N}$ & \\
\hline PPARGC1A & rs2970847 & Exon 8 & $Y$ & 0.037 & $\begin{array}{c}\mathrm{Y} \\
\text { (rs768695) }\end{array}$ & 0.0276 & $\mathrm{~N}$ & \\
\hline PPARGC1A & rs768695 & Intron 12 & $\mathrm{~N}$ & & $\begin{array}{c}Y \\
(\operatorname{rs} 2970853)\end{array}$ & 0.0262 & $\mathrm{~N}$ & 0.0318 \\
\hline PPARGC1A & rs4235308 & Intron 2 & $\mathrm{~N}$ & & $\begin{array}{c}\mathrm{Y} \\
\text { (rs7672915) }\end{array}$ & 0.0068 & $\mathrm{~N}$ & \\
\hline PPARGC1A & rs2970870 & Promoter & $Y$ & 0.025 & $\mathrm{~N}$ & & N & \\
\hline PPARG & rs3856806 & Exon 7 & $Y$ & 0.010 & $\mathrm{~N}$ & & $\mathrm{~N}$ & \\
\hline PPARGC1A & rs1873532 & Intron 10 & $\mathrm{~N}$ & & N & & $\begin{array}{c}\mathrm{Y} \\
(\text { PPARA, rs4253655) }\end{array}$ & 0.0214 \\
\hline PPARGC1A & rs4697046 & Intron 2 & $\mathrm{~N}$ & & N & & $\begin{array}{c}\mathrm{Y} \\
(\text { PPARG, rs1151996) }\end{array}$ & 0.0163 \\
\hline PPARGC1A & rs7672915 & Intron 2 & $\mathrm{~N}$ & & $\mathrm{~N}$ & & $\begin{array}{c}\mathrm{Y} \\
\text { (PPARA, rs4253655) }\end{array}$ & 0.0212 \\
\hline
\end{tabular}

N, no; Y, yes.

"master switch" for the metabolic remodeling of the heart, particularly when coactivated by PPARGC1A [3639]. PPARA expression is down-regulated in the adapted, hypertrophied pressure-overloaded heart and reactivation of PPARA by an agonist is associated with contractile dysfunction[40]. Cardiac-restricted overexpression of PPARA results in hypertrophy, the activation of gene markers of pathologic hypertrophic growth, and in systolic dysfunction[32]. PPARG, on the other hand, plays a critical role in modulating the substrate environment of the heart by its actions in adipocytes[41]. Myocardial fatty acid metabolism has also been more specifically associated with indices of $\mathrm{LV}$ diastolic function in animal models and in humans[1-3,42,43]. In an animal study, PPARA reduced myocardial fibrosis and prevented the development of diastolic dysfunction[44]. Ciglitazole (a PPARG agonist) has also been shown to attenuate LVDD in pressure-overloaded rats[45]. PPARGC1A is a key regulator of cardiac energy metabolism; overexpression of PPARGC1A in the murine heart leads to a modest increase in mitochondrial number, derangements of mitochondrial ultrastructure, and development of cardiomyopathy[32,46]. Thus, there is ample evidence to support a critical role for PPAR-complex genes in regulating cardiac structure and function. However, the precise molecular mechanisms by which these alterations may modulate LVDF remain uncertain.

Several lines of evidence support the existence of genetic association between LVDF and PPAR-complex genes in humans. Recent reports have shown associations between cardiovascular traits and 4 of the 19 SNPs indentified in the present study. The most widely published among these, a synonymous coding PPARGC1A SNP rs2970847 (T394T), has been associated individually, in combination with other PPARGC1A SNPs in haplotype blocks, and in gene-gene interactions with relevant traits including diabetes risk, glucose uptake, obesity, and DNA damage in a variety of populations [47-54]. Intriguingly, this SNP has also been associated with non-hypertensive LVH in a cohort including 270 hypertrophic cardiomyopathy and 2486 hypertensive patients (with and without $\mathrm{LVH}$ ), yielding an odds ratio 1.49 (95\% confidence interval, 1.15-1.98)[55]. The significant PPARGC1A SNP rs4697046 has also been linked with plasma glucose and DNA damage[56]. In our study, this SNP was found to interact with two other PPARGC1A SNPs, although these SNPs were not found to share significant linkage disequilibrium (data not shown), thus implicating cis-acting regulatory elements.

This study also identified two SNPs (rs3856806 in PPARG and rs4253623 in PPARA) as associated with MI risk [57-59]. The rare allele of PPARG SNP rs3856806 has been linked with not only coronary artery disease progression, but also with pro-inflammatory cytokines (MMP9 and TNF $\alpha$ ), plasma homocysteine levels, and obesity [60-62]. The minor allele of PPARA alternate promoter SNP, rs4253623, along with another significant PPARA promoter SNP rs4253681, is clustered adjacent to alternatively-spliced untranslated exons $1 \mathrm{~A}$ and $2 \mathrm{~A}$ and may play a role in regulating PPARA gene expression by mediating the expression of the 6 alternative spliced vari- 


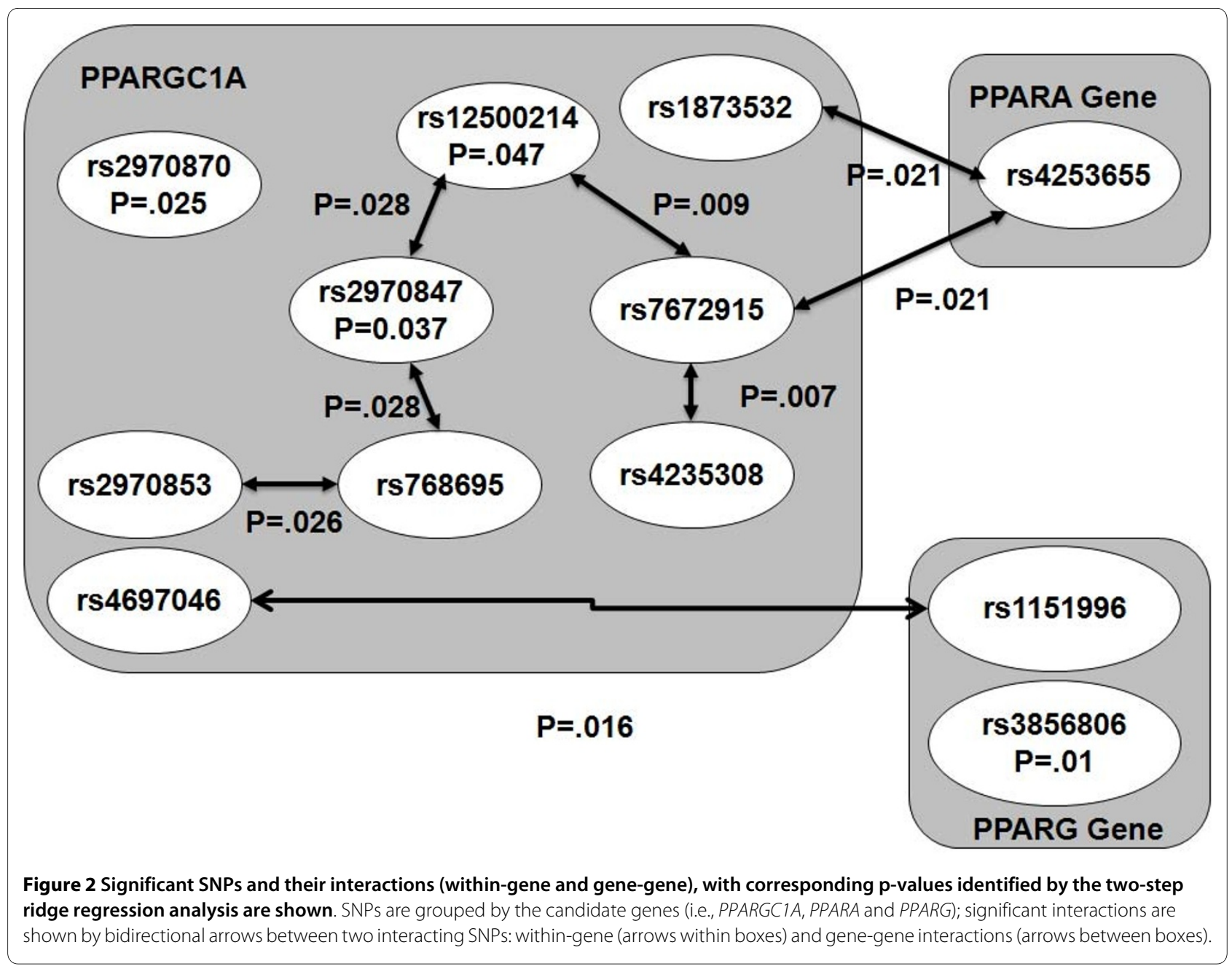

ants resulting from 4 different promoters[63]. Thus, it is plausible that variants in PPAR-complex genes may modulate LVDF-related traits in humans. However, all these possible mechanisms deserve to be explored further in animal models.

\section{Utility of ICA for study of genetic association}

The present study was performed using state-of-the-art analysis techniques in genetic epidemiology and represents a continuation of our study of the genetics of hypertensive heart disease through analysis of endophenotypes, which lay proximal along the pathway from observed clinical phenotype to genotype[8]. The latent factor analysis by ICA was used to address the multidimensional data in which non-Gaussian structure such as clustering and independence represent important components. Although several echocardiographic measures are considered jointly to clinically ascertain LVDF, the precise diagnosis of LVDD remains controversial and there currently exists no universally accepted diagnostic criteria $[4,64,65]$. Furthermore, many echocardiographic endophenotypes are characterized by age-dependency and non-linear associations with disease severity, presenting additional challenges for genetic association studies of this common, complex disease. The ICA trait is extracted from a panel of measured echocardiographyderived endophenotypes, which themselves represent traits more proximal to the genetic underpinnings, and as such has emerged as an important tool in the study of complex diseases[66,67]. ICA is well-suited to the study of LVDF because it effectively reduces the number of dimensions by identifying linear representations of the original endophenotypes. The ICA-derived latent LVDF trait showed significant associations with 7 PPAR-complex SNPs, whereas a range of 0 to 4 SNPs were associated with each of the 14 echocardiography-derived endophenotypes. The frequency distribution of $\mathrm{P}$ values showed a greater proportion of significant associations with the latent LVDF trait than for the measured echocardiography-derived endophenotypes, suggesting that analyses of the latent trait improved detection of the genetic underpinnings of LVDF. Thus, use of ICA-derived latent LVDF trait improved our ability to detect the genetic underpinning of LVDD, as our group and others have 
previously shown for other echocardiography-derived endophenotypes $[8,68]$.

The ridge regression method was used to handle collinearity among SNPs, and thus allowed for testing many SNPs simultaneously. Since these three PPAR-complex genes are all related to fatty acid metabolism, and LVDD is a complex disease, epistasis may contribute to LVDF. Thus, there was a real possibility of collinearity among SNPs, a result of multiple makers exhibiting strong linkage disequilibrium (LD) in a single genomic region. The presence of LD between SNPs at neighboring loci can make it difficult to distinguish functionally relevant variations from nonfunctional variations. However, the application of ridge regression to the evaluation of SNP-SNP interactions provided a robust method to control for the effect of collinearity.

Finally, we investigated within-gene and gene-gene SNP-SNP interactions using a two-stage procedure as outlined in the methods. This led to interesting findings of interaction effects that were not detected by testing for marginal effects alone. This last issue is of particular importance as supported by recent studies in yeast showing that "pure" interactions (with little or negligible marginal effects) are both real and important[69].

\section{Conclusions}

ICA-derived latent LVDF traits improved the ability to detect genetic underpinnings of LVDF. Significant genetic associations were found between PPAR-complex gene variants and LVDF, suggesting that these genes may be involved in the pathogenesis of this complex disease. Although these findings of association are suggestive, these results need to be validated by mechanistic studies in animal models. Pharmacologic modulation of myocardial substrate environment, $P P A R$-complex genes, and/or both may be an important target to restore myocardial metabolic function and thus normalization of left ventricular diastolic function.

\section{Additional material}

Additional file 1 Supplementary Tables and Figures. Table S1. Eleven

LVDD-related echocardiographic parameters in the ICA analysis. Table S2. Absolute echocardiographic parameter loadings of 2-, 3-, 6-component ICA. Table S3. Spearman's correlation coefficients between traditional cardiovascular risk factors and the latent LVDF trait. Table S4. Descriptive statistics for primary echocardiographic endophenotypes (2 components set). Table S5. Descriptive statistics for primary echocardiographic endophenotypes (3 components set). Table S6. Descriptive statistics for primary echocardiographic endophenotypes (6 components set). Table S7A-C. Characteristics of 39 SNPS in the PPARGC1A, PPARA, and PPARG genes. Figure S1. Plots of echocardiographic endophenotype loadings of E21 and E22. Figure S2. Plots of echocardiographic endophenotype loadings of E31, E32 and E33. Figure S3. Plots of echocardiographic endophenotype loadings of E61-E66. Figure S4. Haploview LD display of 34 PPARGC1A SNPS. Figure S5. Haploview LD display of 15 PPARA SNPs. Figure S6. Haploview LD display of the 14 PPARG SNPS. Figure S7. Comparison of the distributions of $P$ values between latent LVDD trait (E61) and primary 14 echocardiographic endophenotypes.

\section{Abbreviations}

(DHF): diastolic heart failure; (DT): deceleration time; (HHD): hypertensive heart disease; (HF): heart failure; (HWE): Hardy-Weinberg equilibrium; (IC): independent components; (ICA): independent component analysis; (IVRT): isovolumic relaxation time; (LD): linkage disequilibrium; (LV): left ventricular; (LVDF): left ventricular diastolic function; (LVH): Left Ventricular hypertrophy; (LVSD): left ventricular systolic dysfunction; (PPAR): peroxisome proliferator-activated receptor; (PWD): Pulse-wave Doppler; (SNPs): single nucleotide polymorphisms; (TDI): Tissue Doppler Imaging.

\section{Competing interests}

The authors declare that they have no competing interests.

\section{Authors' contributions}

JMJ conceived and designed the study, performed statistical analyses, interpret the data, and drafted the manuscript. LdIF conceived and designed the study, performed statistical analyses, warranted the quality of the genetic data, interpret the data, and provided a substantive review of the manuscript. ADW conceived and designed the study, collected and warranted the quality of the echocardiographic phenotype data and provided a substantive review of the manuscript. CG performed statistical analyses, interpret the data, and provided a substantive review of the manuscript. VGD-R conceived and designed the study, interpret the data, offered the guidance on the whole study and provided a substantive review of the manuscript. All authors have read and approved the final manuscript

\section{Acknowledgements}

The authors would like to acknowledge Joann Reagan, RN, BSN, and Sharon Heuerman, RN, for their assistance with subject recruitment and phenotypic characterization. This research was supported in part by NIH grants R01HL71782 (V.G.D.-R.), R21HL094668, KL2RR024994 and K12RR023249 (L.d.I.F.), AHA0855626G (C.C.G), UL1RR024992 (Clinical and Translational Sciences Award to Washington University), and from the Robert Wood Johnson (L.d.I.F.) and Barnes-Jewish Hospital (V.G.D.-R.) Foundations. Genotyping for PPARGC1A, PPARA, and PPARG was provided, in part, by an award from the SeattleSNPs Program for Genomic Applications (L.d.I.F.).

\section{Author Details}

1 Cardiovascular Imaging and Clinical Research Core Laboratory, Cardiovascular Division, Department of Medicine, Washington University School of Medicine, St. Louis, Missouri, USA, 2Division of Biostatistics, Washington University School of Medicine, St. Louis, Missouri, USA, 3Department of Genetics, Washington University School of Medicine, St. Louis, Missouri, USA and ${ }^{4}$ Division of Cardiology, Department of Internal Medicine, National Taiwan University Hospital and National Taiwan University College of Medicine, Taipei, Taiwan

Received: 5 September 2009 Accepted: 28 April 2010

Published: 28 April 2010

References

1. Zile MR, Brutsaert DL: New concepts in diastolic dysfunction and diastolic heart failure: Part II: causal mechanisms and treatment. Circulation 2002, 105(12):1503-1508.

2. Tian $\mathrm{R}$, Nascimben $\mathrm{L}$, Ingwall JS, Lorell $\mathrm{BH}$ : Failure to maintain a low ADP concentration impairs diastolic function in hypertrophied rat hearts. Circulation 1997, 96(4):1313-1319.

3. Christoffersen C, Bollano E, Lindegaard ML, Bartels ED, Goetze JP Andersen CB, Nielsen LB: Cardiac lipid accumulation associated with diastolic dysfunction in obese mice. Endocrinology 2003, 144(8):3483-3490.

4. Nagueh SF, Appleton CP, Gillebert TC, Marino PN, Oh JK, Smiseth OA, Waggoner AD, Flachskampf FA, Pellikka PA, Evangelista A: Recommendations for the evaluation of left ventricular diastolic function by echocardiography. JAm Soc Echocardiogr 2009, 22(2):107-133.

5. How to diagnose diastolic heart failure. European Study Group on Diastolic Heart Failure. Eur Heart J 1998, 19(7):990-1003.

6. Redfield MM, Jacobsen SJ, Burnett JC Jr, Mahoney DW, Bailey KR, Rodeheffer RJ: Burden of systolic and diastolic ventricular dysfunction in the community: appreciating the scope of the heart failure epidemic. JAMA 2003, 289(2):194-202.

7. Lloyd-Jones D, Adams R, Carnethon M, De Simone G, Ferguson TB, Flegal K, Ford E, Furie K, Go A, Greenlund K, et al: Heart Disease and Stroke 
Statistics--2009 Update. A Report From the American Heart Association Statistics Committee and Stroke Statistics Subcommittee. Circulation 2008, 119(3):e21-181.

8. Gu CC, Flores HR, de las Fuentes L, Davila-Roman VG: Enhanced detection of genetic association of hypertensive heart disease by analysis of latent phenotypes. Genet Epidemio/ 2008, 32(6):528-538

9. de las Fuentes L, Brown AL, Mathews SJ, Waggoner AD, Soto PF, Gropler RJ, Davila-Roman VG: Metabolic syndrome is associated with abnormal left ventricular diastolic function independent of left ventricular mass. Eur Heart J 2007, 28(5):553-559

10. Schiller NB, Shah PM, Crawford M, DeMaria A, Devereux R, Feigenbaum H, Gutgesell H, Reichek N, Sahn D, Schnittger I, et al.: Recommendations for quantitation of the left ventricle by two-dimensional echocardiography. American Society of Echocardiography Committee on Standards, Subcommittee on Quantitation of Two-Dimensional Echocardiograms. J Am Soc Echocardiogr 1989, 2(5):358-367.

11. de Simone G, Kizer JR, Chinali M, Roman MJ, Bella JN, Best LG, Lee ET, Devereux RB: Normalization for body size and population-attributable risk of left ventricular hypertrophy: the Strong Heart Study. Am J Hypertens 2005, 18(2 Pt 1):191-196.

12. de Simone G, Daniels SR, Devereux RB, Meyer RA, Roman MJ, de Divitiis O, Alderman MH: Left ventricular mass and body size in normotensive children and adults: assessment of allometric relations and impact of overweight. J Am Coll Cardiol 1992, 20(5):1251-1260.

13. Quinones MA, Otto CM, Stoddard M, Waggoner A, Zoghbi WA Recommendations for quantification of Doppler echocardiography: a report from the Doppler Quantification Task Force of the Nomenclature and Standards Committee of the American Society of Echocardiography. J Am Soc Echocardiogr 2002, 15(2):167-184.

14. Wang M, Yip GW, Wang AY, Zhang Y, Ho PY, Tse MK, Lam PK, Sanderson JE: Peak early diastolic mitral annulus velocity by tissue Doppler imaging adds independent and incremental prognostic value. J Am Coll Cardiol 2003, 41(5):820-826

15. Dumesnil JG, Paulin C, Pibarot P, Coulombe D, Arsenault M: Mitral annulus velocities by Doppler tissue imaging: practical implication with regard to preload alterations, sample position, and normal values. $J$ Am Soc Echocardiogr 2002, 15(10 Pt 2):1226-1231.

16. Nagueh SF, Middleton KJ, Kopelen HA, Zoghbi WA, Quinones MA Doppler tissue imaging: a noninvasive technique for evaluation of left ventricular relaxation and estimation of filling pressures. J Am Coll Cardiol 1997, 30(6):1527-1533.

17. Ommen SR, Nishimura RA, Appleton CP, Miller FA, Oh JK, Redfield MM, Tajik AJ: Clinical utility of Doppler echocardiography and tissue Doppler imaging in the estimation of left ventricular filling pressures: A comparative simultaneous Doppler-catheterization study. Circulation 2000, 102(15):1788-1794.

18. Hyvarinen A, Karhunen J, Oja E: Independent Component Analysis. Wiley New York; 2001

19. Hyvarinen A, Oja E: Independent component analysis: algorithms and applications. Neural Netw 2000, 13(4-5):411-430.

20. Team RDC: R: A language and environment for statistical computing. $R$ Foundation for Statistical Computing, Vienna, Austria; 2005. ISBN 3900051-07-0

21. Malo N, Libiger O, Schork NJ: Accommodating linkage disequilibrium in genetic-association analyses via ridge regression. Am J Hum Genet 2008, 82(2):375-385.

22. Gauderman W, Morrison J: QUANTO 1.1: A computer program for power and sample size calculations for genetic-epidemiololgystudies. 2006 [http://hydra.usc.edu/gxe/].

23. Manolio TA, Collins FS, Cox NJ, Goldstein DB, Hindorff LA, Hunter DJ, McCarthy MI, Ramos EM, Cardon LR, Chakravarti A, et al:: Finding the missing heritability of complex diseases. Nature 2009, 461(7265):747-753.

24. Chiu HC, Kovacs A, Blanton RM, Han X, Courtois M, Weinheimer C, Yamada KA, Brunet S, Xu H, Nerbonne JM, et al:: Transgenic expression of fatty acid transport protein 1 in the heart causes lipotoxic cardiomyopathy. Circ Res 2005, 96(2):225-233.

25. Bing RJ, Siegel A, Ungar I, Gilbert M: Metabolism of the human heart. II. Studies on fat, ketone and amino acid metabolism. Am J Med 1954 16(4):504-515
26. Goodwin GW, Taylor CS, Taegtmeyer H: Regulation of energy metabolism of the heart during acute increase in heart work. J Biol Chem 1998, 273(45):29530-29539.

27. de las Fuentes L, Herrero P, Peterson LR, Kelly DP, Gropler RJ, DavilaRoman VG, (eds): Myocardial fatty acid metabolism: independent predictor of left ventricular mass in hypertensive heart disease. 2003

28. Chiu HC, Kovacs A, Ford DA, Hsu FF, Garcia R, Herrero P, Saffitz JE, Schaffer JE: A novel mouse model of lipotoxic cardiomyopathy. $J$ Clin Invest 2001, 107(7):813-822

29. Zhou YT, Grayburn P, Karim A, Shimabukuro M, Higa M, Baetens D, Orci L, Unger RH: Lipotoxic heart disease in obese rats: implications for human obesity. Proc Natl Acad Sci USA 2000, 97(4):1784-1789.

30. Shimabukuro M, Higa M, Zhou YT, Wang MY, Newgard CB, Unger RH: Lipoapoptosis in beta-cells of obese prediabetic $\mathrm{fa} / \mathrm{fa}$ rats. Role of serine palmitoyltransferase overexpression. J Biol Chem 1998, 273(49):32487-32490

31. Shimabukuro $M$, Zhou $Y T$, Levi $M$, Unger RH: Fatty acid-induced beta cell apoptosis: a link between obesity and diabetes. Proc Nat/ Acad Sci USA 1998, 95(5):2498-2502.

32. Finck BN, Lehman JJ, Leone TC, Welch MJ, Bennett MJ, Kovacs A, Han X, Gross RW, Kozak R, Lopaschuk GD, et al.: The cardiac phenotype induced by PPARA Ipha overexpression mimics that caused by diabetes mellitus. J Clin Invest 2002, 109(1):121-130.

33. Finck BN, Lehman JJ, Leone TC, Welch MJ, Bennett MJ, Kovacs A, Han X, Gross RW, Kozak R, Lopaschuk GD, et al:: The cardiac phenotype induced by PPARA Ipha overexpression mimics that caused by diabetes mellitus. Journal of Clinical Investigation 2002, 109(1):121-130

34. Lehman JJ, Barger PM, Kovacs A, Saffitz JE, Medeiros DM, Kelly DP: Peroxisome proliferator-activated receptor gamma coactivator-1 promotes cardiac mitochondrial biogenesis. J Clin Invest 2000 106(7):847-856

35. Barger PM, Brandt JM, Leone TC, Weinheimer CJ, Kelly DP: Deactivation of peroxisome proliferator-activated receptor-alpha during cardiac hypertrophic growth. J Clin Invest 2000, 105(12):1723-1730.

36. Barger PM, Kelly DP: PPAR signaling in the control of cardiac energy metabolism. Trends Cardiovasc Med 2000, 10(6):238-245

37. Taegtmeyer $\mathrm{H}$ : Switching metabolic genes to build a better heart. Circulation 2002, 106(16):2043-2045

38. Kelly DP: PPARs of the heart: three is a crowd. Circ Res 2003, 92(5):482-484

39. Vega RB, Huss JM, Kelly DP: The coactivator PGC-1 cooperates with peroxisome proliferator-activated receptor alpha in transcriptional control of nuclear genes encoding mitochondrial fatty acid oxidation enzymes. Mol Cell Biol 2000, 20(5):1868-1876.

40. Young ME, Laws FA, Goodwin GW, Taegtmeyer H: Reactivation of peroxisome proliferator-activated receptor alpha is associated with contractile dysfunction in hypertrophied rat heart. J Biol Chem 2001, 276(48):44390-44395

41. Semple RK, Chatterjee VK, O'Rahilly S: PPAR gamma and human metabolic disease. J Clin Invest 2006, 116(3):581-589.

42. Leichman JG, Aguilar D, King TM, Vlada A, Reyes M, Taegtmeyer H: Association of plasma free fatty acids and left ventricular diastolic function in patients with clinically severe obesity. Am J Clin Nutr 2006, 84(2):336-341

43. Nakayama H, Morozumi $T$, Nanto $S$, Shimonagata $T$, Ohara T, Takano $Y$, Kotani J, Watanabe T, Fujita M, Nishio M, et al:: Abnormal myocardial free fatty acid utilization deteriorates with morphological changes in the hypertensive heart. Jpn Circ J 2001, 65(9):783-787.

44. Ogata T, Miyauchi T, Sakai S, Takanashi M, Irukayama-Tomobe Y Yamaguchi I: Myocardial fibrosis and diastolic dysfunction in deoxycorticosterone acetate-salt hypertensive rats is ameliorated by the peroxisome proliferator-activated receptor-alpha activator fenofibrate, partly by suppressing inflammatory responses associated with the nuclear factor-kappa-B pathway. J Am Coll Cardio/ 2004, 43(8):1481-1488.

45. Henderson BC, Sen U, Reynolds C, Moshal KS, Ovechkin A, Tyagi N, Kartha GK, Rodriguez WE, Tyagi SC: Reversal of systemic hypertensionassociated cardiac remodeling in chronic pressure overload myocardium by ciglitazone. Int J Biol Sci 2007, 3(6):385-392.

46. Russell LK, Mansfield CM, Lehman JJ, Kovacs A, Courtois M, Saffitz JE, Medeiros DM, Valencik ML, McDonald JA, Kelly DP: Cardiac-specific induction of the transcriptional coactivator peroxisome proliferator- 
activated receptor gamma coactivator-1alpha promotes mitochondrial biogenesis and reversible cardiomyopathy in a developmental stage-dependent manner. Circ Res 2004, 94(4):525-533.

47. Bhat A, Koul A, Rai E, Sharma S, Dhar MK, Bamezai RN: PGC-1alpha Thr394Thr and Gly482Ser variants are significantly associated with T2DM in two North Indian populations: a replicate case-control study. Hum Genet 2007, 121(5):609-614.

48. Rai E, Sharma S, Koul A, Bhat AK, Bhanwer AJ, Bamezai RN: Interaction between the UCP2-866G/A, mtDNA 10398G/A and PGC1alpha p.Thr394Thr and p.Gly482Ser polymorphisms in type 2 diabetes susceptibility in North Indian population. Hum Genet 2007, 122(5):535-540.

49. Su Y, Peng SB, Li ZQ, Huang QY: [Association study between PPARGC1A Thr394Thr/Gly482Ser polymorphisms and type 2 diabetes]. Yi Chuan 2008, 30(3):304-308

50. Zhang SL, Lu WS, Yan L, Wu MC, Xu MT, Chen LH, Cheng H: Association between peroxisome proliferator-activated receptor-gamma coactivator-1alpha gene polymorphisms and type 2 diabetes in southern Chinese population: role of altered interaction with myocyte enhancer factor 2C. Chin Med J (Engl) 2007, 120(21):1878-1885.

51. Vimaleswaran KS, Radha V, Anjana M, Deepa R, Ghosh S, Majumder PP, Rao MR, Mohan V: Effect of polymorphisms in the PPARGC1A gene on body fat in Asian Indians. Int J Obes (Lond) 2006, 30(6):884-891.

52. Vimaleswaran KS, Radha V, Ghosh S, Majumder PP, Deepa R, Babu HN, Rao MR, Mohan V: Peroxisome proliferator-activated receptor-gamma coactivator-1alpha (PGC-1alpha) gene polymorphisms and their relationship to Type 2 diabetes in Asian Indians. Diabet Med 2005 22(11):1516-1521

53. Pihlajamaki J, Kinnunen M, Ruotsalainen E, Salmenniemi U, Vauhkonen I, Kuulasmaa T, Kainulainen S, Laakso M: Haplotypes of PPARGC1A are associated with glucose tolerance, body mass index and insulin sensitivity in offspring of patients with type 2 diabetes. Diabetologia 2005, 48(7):1331-1334.

54. Hara K, Tobe K, Okada T, Kadowaki H, Akanuma Y, Ito C, Kimura S, Kadowaki T: A genetic variation in the PGC-1 gene could confer insulin resistance and susceptibility to Type II diabetes. Diabetologia 2002, 45(5):740-743.

55. Wang S, Fu C, Wang H, Shi Y, Xu X, Chen J, Song X, Sun K, Wang J, Fan X, et al: Polymorphisms of the peroxisome proliferator-activated receptorgamma coactivator-1alpha gene are associated with hypertrophic cardiomyopathy and not with hypertension hypertrophy. Clin Chem Lab Med 2007, 45(8):962-967.

56. Lai CQ, Tucker KL, Parnell LD, Adiconis X, Garcia-Bailo B, Griffith J, Meydani $M$, Ordovas JM: PPARGC1A variation associated with DNA damage, diabetes, and cardiovascular diseases: the Boston Puerto Rican Health Study. Diabetes 2008, 57(4):809-816

57. Enquobahrie DA, Smith NL, Bis JC, Carty CL, Rice KM, Lumley T, Hindorff LA, Lemaitre RN, Williams MA, Siscovick DS, et al: Cholesterol ester transfer protein, interleukin-8, peroxisome proliferator activator receptor alpha, and Toll-like receptor 4 genetic variations and risk of incident nonfatal myocardial infarction and ischemic stroke. Am J Cardiol 2008, 101(12):1683-1688.

58. Szeto CC, Chow KM, Poon PY, Kwan BC, Li PK: Peroxisome proliferatoractivated receptor-gamma gene polymorphism and risk of cardiovascular disease in patients with diabetic nephropathy. Am J Nephrol 2008, 28(5):715-722.

59. Wang XL, Oosterhof J, Duarte N: Peroxisome proliferator-activated receptor gamma C161-->T polymorphism and coronary artery disease. Cardiovasc Res 1999, 44(3):588-594.

60. Rhee EJ, Oh KW, Lee WY, Kim SY, Oh ES, Baek KH, Kang MI, Kim SW: Effects of two common polymorphisms of peroxisome proliferator-activated receptor-gamma gene on metabolic syndrome. Arch Med Res 2006 37(1):86-94

61. Golledge J, Norman PE: Relationship between two sequence variations in the gene for peroxisome proliferator-activated receptor-gamma and plasma homocysteine concentration. Health in men study. Hum Genet 2008, 123(1):35-40.

62. Liu Y, Yuan Z, Zhang J, Yin P, Wang D, Wang Y, Kishimoto C, Ma A: PPARG amma gene $C 161 \mathrm{~T}$ substitution is associated with reduced risk of coronary artery disease and decreased proinflammatory cytokine expression. Am Heart J 2007, 154(4):718-724.
63. Chew CH, Samian MR, Najimudin N, Tengku-Muhammad TS: Molecular characterisation of six alternatively spliced variants and a novel promoter in human peroxisome proliferator-activated receptor alpha. Biochem Biophys Res Commun 2003, 305(2):235-243.

64. Bursi F, Weston SA, Redfield MM, Jacobsen SJ, Pakhomov S, Nkomo VT, Meverden RA, Roger VL: Systolic and diastolic heart failure in the community. JAMA 2006, 296(18):2209-2216.

65. Pedersen F, Raymond I, Madsen LH, Mehlsen J, Atar D, Hildebrandt P: Echocardiographic indices of left ventricular diastolic dysfunction in 647 individuals with preserved left ventricular systolic function. Eur $\mathrm{J}$ Heart Fail 2004, 6(4):439-447.

66. Dick DM, Jones K, Saccone N, Hinrichs A, Wang JC, Goate A, Bierut L, Almasy L, Schuckit M, Hesselbrock V, et al.: Endophenotypes successfully lead to gene identification: results from the collaborative study on the genetics of alcoholism. Behav Genet 2006, 36(1):112-126.

67. Gottesman II, Gould TD: The endophenotype concept in psychiatry: etymology and strategic intentions. Am J Psychiatry 2003, 160(4):636-645.

68. Diebold B, Delouche A, Abergel E, Raffoul H, Diebold H, Frouin F: Optimization of factor analysis of the left ventricle in echocardiography for detecting wall motion abnormalities. Ultrasound Med Biol 2005, 31(12):1597-1606.

69. Gerke J, Lorenz K, Cohen B: Genetic interactions between transcription factors cause natural variation in yeast. Science 2009, 323(5913):498-501.

Pre-publication history

The pre-publication history for this paper can be accessed here: http://www.biomedcentral.com/1471-2350/11/65/prepub

doi: $10.1186 / 1471-2350-11-65$

Cite this article as: Juang et al., Association and interaction of PPAR-complex gene variants with latent traits of left ventricular diastolic function $B M C$ Medical Genetics 2010, 11:65

\section{Submit your next manuscript to BioMed Central and take full advantage of:}

- Convenient online submission

- Thorough peer review

- No space constraints or color figure charges

- Immediate publication on acceptance

- Inclusion in PubMed, CAS, Scopus and Google Scholar

- Research which is freely available for redistribution
C) BioMed Central 